\title{
Xây Dựng Văn Hóa Doanh Nghiệp - Yếu Tố Quyết Định Sự Trường Tồn Của Doanh Nghiệp
}

\author{
L.E.T. Solutions
}

December 12, 2017

https://let.vn/vi/blog/xay-dung-van-hoa-doanh-nghiep-yeu-to-quyet-dinh-sutruong-ton-cua-doanh-nghiep 


\section{Xây Dựng Văn Hóa Doanh Nghiệp - Yếu Tố Quyết Định Sự}

\section{Trường Tồn Của Doanh Nghiệp}

Trang chủ (/) / Blog (/vi/category/default?module=article\&id=55f180b13ebb6)

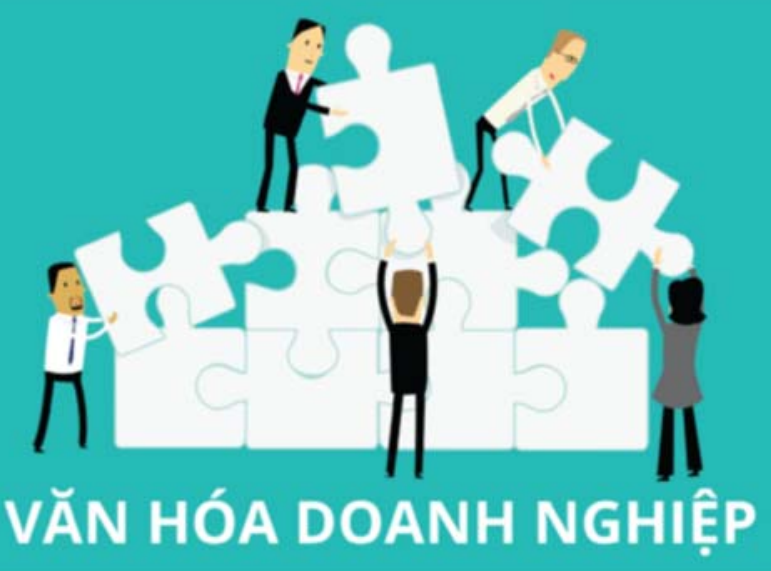

\section{I.Văn hóa doanh nghiệp}

-Văn hóa doanh nghiệp bắt nguồn từ những giá trị.

Cốt lõi của văn hóa doanh nghiệp là tinh thần doanh nghiệp và quan điểm giá trị của doanh nghiệp. Trong cuốn sách Văn mình làm giàu và nguồn gốc của cải của TS. Vương Quân Hoàng, chúng ta đã được đề cập tới khái niệm giá trị. Giải thích một cách đơn giản, giá trị là một cái gì đó mà người ta cảm thấy quan trọng, có ích. Cụm từ "Quan trọng" và "Có ích lợi" là rất đáng lưu tâm trong xây dựng văn hóa doanh nghiệp. Bởi lẽ lãnh đạo công ty sẽ rất khó xây dựng văn hóa doanh nghiệp, nếu không truyền đạt được những ích lợi mà văn hóa doanh nghiệp đem lại. Nhân viên cần được giáo dục nhận thức rằng việc đeo thẻ nhân viên, mặc đồng phục là thể hiện sự tự hào là thành viên của công ty, và có ích cho công việc của họ chứ không phải họ mang những thứ đó để làm quảng cáo.

Rất nhiều lãnh đạo đã mắc lỗi khi áp đặt văn hóa mà không khơi gợi nhận thức của nhân viên mình với các giá trị văn hóa. Nếu không giảng giải được cặn kẽ hệ thống các giá trị văn hóa của doanh nghiệp có ích lợi gì với nội bộ tổ chức, tất yếu moi hình thức triển khai chỉ là phong trào. Một câu hỏi được đặt ra rằng, vậy những giá trị nào là hợp iỳ va gia trị năo la knong hợp Iy. Đièu nayy tuy thuọ̣ rất nhiều vào từng

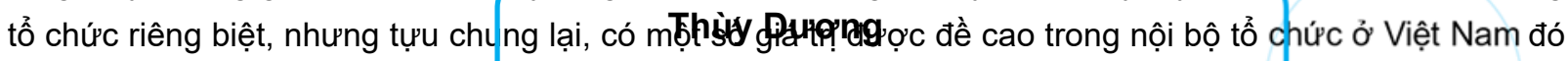
là:

Xin chào anh/chị!

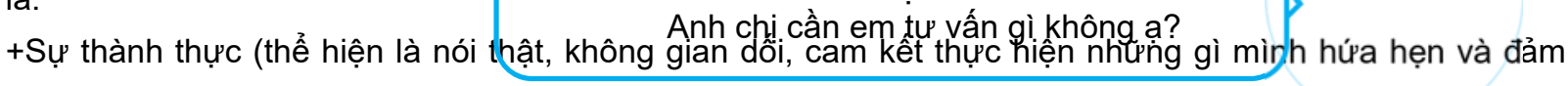
bảo đúng những gì mình sẽ thực hiện)

+Sự tự giác (thể hiện ở mức độ sã̃n sàng với công việc, không ngại khó khăn, làm việc hết mình vì lợi ích 
của tổ chức)

+Sự khôn khéo (biết nói những gì cần nói, hỏi những điều cần hỏi, tranh luận những điều đáng tranh luận và sắp xếp những gì hợp lý nhất)

+Ngoài ra còn một số giá trị khác được đề cập tới như sự tự tin, sáng tạo ... Những giá trị này sẽ là nền tảng định hướng cho văn hóa của doanh nghiệp.

-Văn hóa có cả biểu hiện hữu hình và vô hình.

Một số biểu hiện rất dễ quan sát, đó là lớp bề mặt của văn hóa, còn phần lõi có ảnh hưởng sâu và mạnh hơn rất nhiều thì vô hình.

+Lớp bề mặt của văn hóa doanh nghiệp-biểu hiện hữu hình: Trang phục làm việc, môi trường làm việc, lợi ích, khen thưởng, cấu trúc tổ chức, các mối quan hệ,...

+Phần lõi-biểu hiện vô hình: Các giá trị, thái độ, niềm tin, tiêu chuẩn, giả định,...

Bản chất của văn hóa doanh nghiệp là đối nội phải tăng cường tiềm lực, quy tụ được sức sáng tạo của công nhân viên chức, khích lệ họ sáng tạo ra nhiều lợi nhuận cho doanh nghiệp; đối ngoại phải được xã hội bản địa chấp nhận.

Văn hóa doanh nghiệp được thể hiện ở nhiều cấp độ khác nhau. Cấp dễ thấy nhất thể hiện ngay trong công việc hàng ngày nhưng cách báo cáo công việc, giữ gìn tài sản chung, ngôn ngữ khi giao tiếp với đồng nghiệp, đối tác, khách hàng, các thủ tục hành chính... Cấp thứ hai là các giá trị tinh thần xác định việc phải làm, hành động của mình đúng hay sai, có mang lại lợi ích hay thiệt hại chung hay không. Đây là điều Lãnh đạo doanh nghiệp mong muốn nhận được ở nhân viên và phải xây dựng dần từng bước. Cấp thứ ba là nền tảng cho các hành động chính là niềm tin, nhận thức, suy nghĩ và xúc cảm được coi là đương nhiên ăn sâu trong tiềm thức mỗi cá nhân trong doanh nghiệp. Các ngầm định nền tảng này là nền tảng cho các giá trị và hành động của mỗi thành viên. Văn hóa kinh doanh trong một tổ chức đã tiến đến mức độ cao nhất, trở thành một thứ Đạo, mà từ thế hệ này tới thế hệ khác tôn sùng và làm theo.

\section{II.Tác dụng của văn hóa doanh nghiệp}

Văn hóa doanh nghiệp quyết định sự trường tồn của doanh nghiệp. Nó giúp doanh nghiệp trường tồn vượt xa cuộc đời của những người sáng lập. Nhiều người cho rằng văn hóa doanh nghiệp là một tài sản của doanh nghiệp. Tác dụng của văn hóa doanh nghiệp thể hiện:

-Tạo động lực làm việc

Văn hóa doanh nghiệp giúp nhân viên thấy rõ mục tiêu, định hướng và bản chất công việc mình làm. Văn hóa doanh nghiệp còn tạo ra các mối quan hệ tốt đẹp giữa các nhân viên và một môi trường làm việc thoải mái, lành mạnh. Văn hóa doanh nghiệp phù hợp giúp nhân viên có cảm giác mình làm công việc có ý nghĩa hãnh diện vì là một thành viên của doanh nghiệp. Điều này càng có ý nghĩa rất lớn khi tình trạng "chảy máu chất xám" đang phổ biến. Lương và thu nhập chỉ là một phần của động lực làm việc. Khi thu nhập đạt đến một mức nào đó, người ta sã̃n sàng đánh đổi chọn mức thu nhập thấp hơn để được làm việc ở một môi trường hoà đồng, thoải mái, được đồng nghiệp tôn trọng.

-Điều phối và kiểm soát

Văn hóa doanh nghiệp điều phối và kiểm soát hành vi cá nhân bằng các chuẩn mực, thủ tục, quy trình, quy tắc... Khi phải ra một quyết định phức tạp, văn hoá doanh nghiệp giúp ta thu hẹp phạm vi các lựa chọn phải xem xét.

-Giảm xung đột

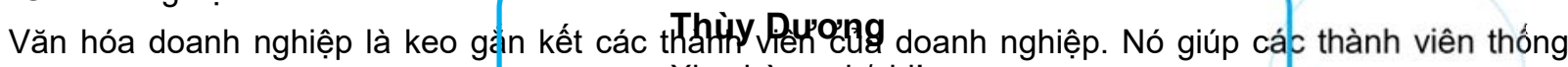

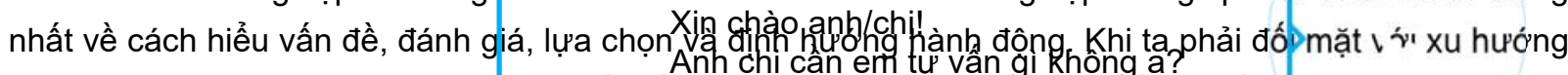
xung đột lẫn nhau thì văn hoá chilhh là yếu tố giúp mọi người hoà nhập và thống nhất.

-Lợi thế cạnh tranh

Tổng hợp các yếu tố gắn kết, điều phối, kiểm soát, tạo động lực... làm tăng hiệu quả hoạt động và tạo sự 
khác biệt trên thị trường. Hiệu quả và sự khác biệt sẽ giúp doanh nghiệp cạnh tranh tốt trên thị trường.

\section{III.Đặc trưng của văn hóa doanh nghiệp}

Văn hóa doanh nghiệp có ba nét đặc trưng, đó là:

- Văn hóa doanh nghiệp mang "tính nhân sinh", tức là gắn với con người. Tập hợp một nhóm người cùng làm việc với nhau trong tổ chức sẽ hình thành nên những thói quen, đặc trưng của đơn vị đó. Do đó, văn hóa doanh nghiệp có thể hình thành một cách "tự phát" hay "tự giác". Theo thời gian, những thói quen này sẽ trở nên rõ ràng hơn và hình thành ra "cá tính" riêng của đơn vị. Nên, một doanh nghiệp, dù muốn hay không, đều sẽ dần hình thành văn hoá của tổ chức mình. Văn hóa doanh nghiệp khi hình thành một cách tự phát có thể phù hợp với mong muốn và mục tiêu phát triển của tổ chức hoặc không. Chủ động tạo ra những giá trị văn hoá mong muốn là điều cần thiết nếu doanh nghiệp muốn văn hóa thực sự phục vụ cho định hướng phát triển chung, góp phần tạo nên sức mạnh cạnh tranh của mình.

- Văn hóa doanh nghiệp có "tính giá trị". Không có văn hóa doanh nghiệp "tốt" và "xấu" (cũng như cá tính, không có cá tính tốt và cá tính xấu), chỉ có văn hoá phù hợp hay không phù hợp (so với định hướng phát triển của doanh nghiệp). Giá trị là kết quả thẩm định của chủ thể đối với đối tượng theo một hoặc một số thang độ nhất định; và những nhận định này được thể hiện ra thành "đúng-sai", "tốt-xấu", "đẹp-xấu"..., nhưng hàm ý của "sai" của "xấu", về bản chất, chỉ là "không phù hợp". Giá trị cũng là khái niệm có tính tương đối, phụ thuộc vào chủ thể, không gian và thời gian. Trong thực tế, người ta hay áp đặt giá trị của mình, của tổ chức mình cho người khác, đơn vị khác, nên dễ có những nhận định "đúng-sai" về văn hoá của một doanh nghiệp nào đó.

- Văn hóa doanh nghiệp có "tính ổn định". Cũng như cá tính của mỗi con người, văn hoá doanh nghiệp khi đã được định hình thì "khó thay đổi". Qua thời gian, các hoạt động khác nhau của các thành viên doanh nghiệp sẽ giúp các niềm tin, giá trị được tích lũy và tạo thành văn hoá. Sự tích lũy các giá trị tạo nên tính ổn định của văn hoá.

\section{IV.Những yếu tố cấu thành văn hóa doanh nghiệp}

Cấu trúc của văn hóa doanh nghiệp gồm 5 lớp:

- Triết lý quản lý và kinh doanh: Đây là lớp trong cùng và quan trọng nhất của văn hóa doanh nghiệp, bao gồm những triết lý quản lý và kinh doanh cốt lõi nhất, căn bản nhất. Đây là cơ sở xây dựng định hướng hoạt động của doanh nghiệp và chi phối các quyết định quản lý; là niềm tin, là giá trị bền vững không thay đổi bất chấp thời gian và ngoại cảnh. Vì vậy, điều kiện tiên quyết để quá trình xây dựng văn hóa doanh nghiệp thành công là sự cam kết của những người lãnh đạo cao nhất của doanh nghiệp. Bởi, phần quan trọng nhất, trái tim và khối óc của doanh nghiệp nằm ở lớp trong cùng của văn hóa, xin nhắc lại, đó là triết lý kinh doanh, phương châm quản lý của doanh nghiệp và chỉ có những nhà quản lý cao nhất của doanh nghiệp mới đủ khả năng tác động đến lớp văn hóa cốt lõi này.

- Động lực của cá nhân và tổ chức: Lớp yếu tố quan trọng thứ hai của văn hóa doanh nghiệp chính là các động lực thúc đẩy hành động của các cá nhân, và môi trường "động lực chung" của tổ chức. Các yếu tố động lực này sẽ biểu hiện ra ngoài bằng những hành vi hàng ngày của các cá nhân trong doanh nghiệp.

- Qui trình qui định: Qui trình, qui định, chính sách giúp doanh nghiệp hoạt động ổn định. Đây cũng là cấu thành giúp doanh nghiệp đáp ứng các yêu cầu ngày càng cao về chất lượng sản phẩm dịch vụ của doanh nghiệp, góp phần tạo tính ổn địnn và nâng cạh hiệy qưở của doanh nghiệp với nỗ lực làm hài lòng khách hàng và xã hội.

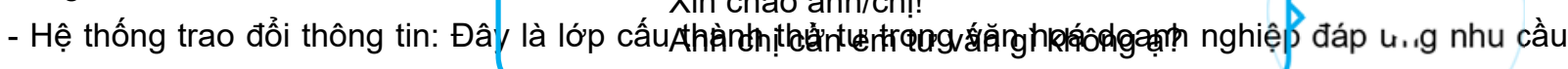
thông tin quản lý đa dạng, đa chiều, chính vác và kịp thời. Hộ thống này cần đảm bảo mọi thông tin cần thiết cho doanh nghiệp đều được thu thập, truyền đạt, lưu trữ và xử lý; đồng thời đảm bảo cho mọi thành viên doanh nghiệp dễ dàng tiếp cận và sử dụng các thông tin cần thiết cho các hoạt động thường nhật 
cũng như công tác lập kế hoạch, xây dựng định hướng chiến lược.

- Phong trào, nghi lễ, nghi thức: Đây là cấu thành văn hoá bề nổi, phản ánh đời sống, sinh hoạt của công ty. Tuy không trực tiếp ảnh hưởng đến kết quả kinh doanh, nhưng ảnh hưởng của nó đối với mọi hoạt động của doanh nghiệp cũng rất lớn. Nó tuyên truyền phổ biến đường lối, chính sách của công ty, tạo ra sự khác biệt của công ty với bên ngoài, tạo hình ảnh tốt cho công ty trước cộng đồng qua đó góp phần xây dựng thương hiệu ... Do vậy, để thực sự tạo ra "cá tính" của doanh nghiệp, tạo ra sức mạnh canh tranh cho doanh nghiệp, doanh nhân, cán bộ quản lý cấp cao, các nhà lãnh đạo và quản lý các cấp khác phải nhất thiết tham gia vào quá trình xây dựng văn hoá của tổ chức mình.

\section{Làm thế nào để xây dựng văn hóa doanh nghiệp}

Thực tế, văn hoá tồn tại khách quan và doanh nghiệp nào cũng có văn hoá của riêng mình. Chỉ có điều văn hoá được thể hiện như thế nào và doanh nghiệp đó có phát hiện ra những giá trị tốt để phát huy và những giá trị chưa tốt để thay đổi hay không. Văn hóa doanh nghiệp bắt nguồn từ những gì nhỏ nhất, cụ thể, không chung chung.

Ông Lê Quân - Chủ tịch Hội đồng chuyên gia EduViet Consultancy cũng đã đưa ra những ví dụ cụ thể để khẳng định tầm quan trọng của văn hóa doanh nghiệp trong đời sống doanh nghiệp. Và theo ông, trong quá trình xây dựng văn hóa doanh nghiệp, cần chú trọng tới việc xác lập và phát triển các giá trị văn hóa cốt lõi của doanh nghiệp, các phương pháp, kỹ thuật xác định và kiểm soát, phát triển các giá trị cốt lõi trong hệ thống văn hóa của doanh nghiệp. "Hệ thống giá trị cốt lõi là động lực chủ yếu thúc đẩy mọi người làm việc, hạt nhân liên kết mọi người trong doanh nghiệp với nhau, liên kết doanh nghiệp với khách hàng, đối tác của doanh nghiệp, liên kết doanh nghiệp với xã hội nói chung" - ông Quân khẳng định.

Ông Phạm Văn Phổ - Chuyên gia EduViet Consultancy, nguyên Viện trưởng Viện Nghiên cứu kinh tế và kinh doanh Hà Nội cho rằng: "Xây dựng văn hóa doanh nghiệp là một quá trình kiên nhẫn, lâu dài và đòi hỏi ý chí lớn lao của từng nhà lãnh đạo, cán bộ công ty”. Và theo ông, để xây dựng văn hóa trong doanh nghiệp, trước hết phải là ý chí xây dựng văn hóa của ban lãnh đạo doanh nghiệp, sau đó phải qua công tác giáo dục để nhân viên hiểu, chấp nhận chia sẻ và đi đến sự đồng thuận trong cộng đồng doanh nghiệp đó. Ngoài ra, muốn xây dựng văn hóa doanh nghiệp thì phải biết phối hợp chặt chẽ giữa các bộ phận trong công ty. Thiếu sự hợp lực này thì văn hóa doanh nghiệp sẽ không xây dựng được.

Ông Hoàng Đình Phi - Chủ tịch HĐQT EduViet và Chủ tịch HĐQT Tập đoàn Sannam đã đưa ra những cơ sở lý luận cơ bản để xây dựng và phát triển trình độ văn hóa doanh nghiệp và ông cho rằng: "đã đến lúc các doanh nghiệp Việt Nam nên nghiên cứu và thành lập thêm một bộ phận quản lý mới trong hệ thống quản trị doanh nghiệp để chuyên quản lý về văn hóa doanh nghiệp".

Văn hóa doanh nghiệp có vô vàn hình thức biểu hiện, nhưng cũng xin lưu ý với những nhà tổ chức, muốn xây dựng văn hóa doanh nghiệp rằng, văn hóa doanh nghiệp không phải thực hiện trong ngày một ngày hai, nó có thể là một chặng đường kéo dài hàng thập kỷ. Việc xây dựng văn hóa doanh nghiệp không phải là một khẩu hiệu, nó phải được sự vun đắp của từng cá nhân trong tổ chức doanh nghiệp đó, xây dựng văn hóa là chìa khóa để doanh nghiệp được trường tồn.

\section{XÂY DỰNG VĂN HÓA DOANH NGHIẸP = THIÉT LẬP CHUẢN MỰC + TẠO THÓI QUEN}

Tóm lại, xây dựng văn hóa doanh nghiệp không đơn thuân là liệt kê ra các giá trị mình mong muốn mà đòi

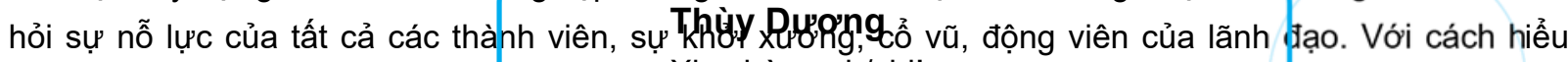

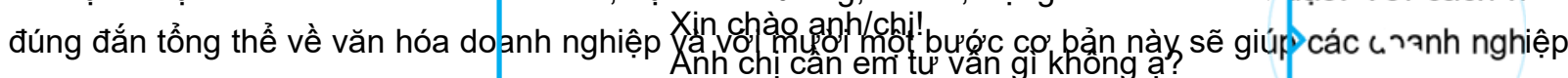
từng bước xây dựng thành công văn hoá cho mình.

(Trích dẫn theo TS Phan Quốc Việt \& Ths. Nguyễn Huy Hoàng,

Trung tâm Phát triển Kỹ năng Con người Tâm Việt) 


\section{Bài đọc nhiều}

Giảm giá lên tới 36\% với chương trình Bitrix24 Summer Supercharger (/vi/blog/giam-gia-lentoi-36-voi-chuong-trinh-bitrix24-summer-supercharger)

"Sail the Sale" - Chương trình giảm giá Bitrix24 lên tới 50\% cho tài khoản Cloud mới (/vi/blog /sail-the-sale-chuong-trinh-giam-gia-bitrix24-len-toi-50-cho-tai-khoan-cloud-moi)

Hướng dẫn sử dụng VPN của trình duyệt Opera khi cáp quang gặp sự cố (/vi/blog/huong-dansu-dung-vpn)

BITRIX24 HALLOWEEN SUPERSALE (/vi/blog/bitrix24-halloween-supersale)

Giảm giá siêu hot cuối năm 2017 (/vi/blog/giam-gia-sieu-hot-cuoi-nam-2017)

Tags

Bitrix24 (/vi/tag/Bitrix24/55f180b13ebb6)

Bitrix24 Tiếng Việt (/vi/tag/Bitrix24+Ti\%E1\%BA\%BFng+Vi\%E1\%BB\%87t/55f180b13ebb6)

Quản lý (/vi/tag/Qu\%E1\%BA\%A3n+|\%C3\%BD/55f180b13ebb6)

Nhân sự (/vi/tag/Nh\%C3\%A2n+s\%E1\%BB\%B1/55f180b13ebb6)

Ưu đãi (/vi/tag/\%C6\%AFu+\%C4\%91\%C3\%A3i/55f180b13ebb6)

sale off (/vi/tag/sale+off/55f180b13ebb6)

giảm giá (/vi/tag/gi\%E1\%BA\%A3m+gi\%C3\%A1/55f180b13ebb6)

\begin{tabular}{l|l|l} 
discount $(/ \mathrm{vi} / \mathrm{tag} /$ discount/55f180b13ebb6) & bitrix24 (/vi/tag/bitrix24/55f180b13ebb6)
\end{tabular}

Quản Lý (/vi/tag/Qu\%E1\%BA\%A3n+L\%C3\%BD/55f180b13ebb6)

Liên hệ

CÔNG TY CỔ PHẦN L.E.T

\section{Thùy Dương}

Xin chào anh/chi!

Anh chị cần em tư vấn gì không ạ?

Số 11 ngõ 71 Võ Chí Công, Nghĩa Đô, Cầu Giấy, Hà Nội 
Tel: 02477744999

Email: contact@let.vn (mailto:contact@let.vn)

Copyright (C) 2015 L.E.T.,JSC. All rights reserved.

f (https://www.facebook.com/letjsc)

viut (https://www.youtube.com/channel/UCwL9e5omOqa0vhjsUT1_vEQ)

() (https://github.com/letyii) 


\section{Tài liệu tham khảo:}

[1] L.E.T. Solutions. (2017). Xây Dựng Văn Hóa Doanh Nghiệp - Yếu Tố Quyết Định Sự Trường Tồn Của Doanh Nghiệp. LET Blog. https://let.vn/vi/blog/xay-dung-van-hoa-doanhnghiep-yeu-to-quyet-dinh-su-truong-ton-cua-doanh-nghiep

[2] Vương Quân Hoàng. (2007). Văn minh làm giàu \& Nguồn gốc của cải. Nxb Chính trị quốc gia, Hà Nội. 